\title{
Mídia e sua influência na sociedade e na política brasileira do século XXI
}

\section{Media and its influence in the society and the brazilian politics in the $21^{\text {st }}$ century}

DOI: $10.46814 / \operatorname{lajdv3n3-023}$

Recebimento dos originais: 23/12/2020

Aceitação para publicação: 26/02/2021

João Marcelo Fernandes

professor da Rede Estadual Paulista. Especialista em Humanidades pela Uenp - CCHE/ Campus Jacarezinho.

\section{Luis De Castro Campos Jr}

professor do curso de História - Uenp- CCHE/ Campus Jacarezinho . Doutor em História - FCL/

Unesp -Campus Assis.

Endereço: Rua Padre Melo 1200 - Jardim Marimar: CEP: 8640-000. Jacarezinho - Pr.

E-mail: castro@uenp.edu.br

\section{RESUMO}

A Mídia tem desempenhado um papel importante na sociedade contemporânea e sua influência chamou a atenção de acadêmicas em várias áreas do conhecimento visando dar uma contribuição para compreender seu grau de abrangência. Fruto da Revolução Industrial, de forma específica de sua segunda grande fase, novas tecnologias passaram a compor o universo de populações deslocadas para o espaço urbano como o desenvolvimento de um novo padrão de vida. No caso específico brasileiro o crescimento do rádio a partir dos anos 40 e da televisão se afirmando nos anos 1970 contribuiu para sua maior aproximação da política e consequente uso por grandes lideranças em torno de projetos voltados para conquista e manutenção de poder. Neste estudo pretende-se compreender a influência midiática na política brasileira logo após o processo de redemocratização de forma específica na eleição presidencial de 1989 que contrapôs Fernando Collor de Melo de Luis Inácio Lula da Silva.

Palavras-chave: Mídia, Sociedade, História, Política, Comunicação.

\begin{abstract}
ABSRACT
The media has developed an important function in the contemporary society and its influence has attracted the attention of students in several areas about the knowledge aiming to understand its degree of coverage. Result of the Industrial Revolution, in a specifically from its second period, new technologies has been started to complete the universe of populations moved to the urban space as the development of a new life standard. Particularly in Brazilian context, the development of radio from the 40s and the television guaranteeing itself in the 1970s contributed to a closer approximation of politics and consequent use by great leaders about the projects aimed at the conquest and maintenance of power. In this study it is aimed to understand the media influence in the Brazilian politics right after the process of specifically in the presidential election in 1989 that opposed Fernando Collor de Mello to Luis Inácio Lula da Silva.
\end{abstract}

Keywords: Media, Society, History, Politcs, Communication. 


\section{INTRODUÇÃO}

O presente artigo tem como objetivo traçar um perfil de como ocorre à intervenção por parte da mídia na formação da opinião pública, bem como na política cotidiana. Os meios de comunicação exercem grande influência pelo fato de ser meio de fácil acesso para quase todas as pessoas, até por isso existem necessidades e interesses ambos os seguimentos e para que eles se solidifiquem, a televisão e o jornal fazem o papel de uma grande vitrine.

Um exemplo são os "filtros" que a notícia passa nas redações através das linhas editoriais até chegar ao seu destino final. Toda narrativa é construída a partir de determinada notícia e há uma intenção de como esse público deve receber e formular sua opinião.

A liberdade de imprensa é uma conquista legítima e imprescindível a todo regime democrático, cuja importância é inquestionável. Entretanto, há de se observar as características peculiares dos meios de comunicação que fazem com que os mesmos sejam formadores de opiniões, o qual é o foco dessa pesquisa. Busca-se aqui discutir e analisar alguns pontos sobre a atual relação entre a mídia e a política brasileira com base em estudos em artigos e textos que trabalham a questão na mídia ao longo da história, observando as mudanças provocadas pela mesma sobre a forma como é vista e praticada a política, o impacto atribuído à mídia sobre os eleitores e o cenário político.

\section{MATERIAIS E MÉTODOS}

O desenvolvimento deste trabalho concentra-se no papel desempenhado pelo Jornal Nacional, o telejornal mais assistido do país, nas eleições de 1989. Analisando a cobertura feita pela emissora durante a campanha política, e pegando a pesquisa Datafolha da época, percebe-se que houve uma desigualdade na cobertura dos dois candidatos. .'Enquanto Collor teve $21.5 \%$ do tempo no Jornal Nacional, entre 28 de agosto e 29 de novembro, Lula obteve apenas 9\%” (NEVES, Flora Apud Rubim, 1989, p.17).

Para ter uma visão mais ampla deste recorte temporal (1989 e 1992) é imprescindível discutir autores que trabalham um contexto mais geral sobre o tema. Se por um lado, a mídia é um instrumento de fortalecimento da democracia, por outro, pode se transformar em aparelho de divulgação e manutenção da ideologia dominante (NEVES, Flora. Telejornalismo e Poder nas eleições presidenciais. São Paulo: Editora Summos, 2008 p.44) 


\section{REVISÃO DE LITERATURA}

Tania Regina de Luca ${ }^{1}$ e Ana Luiza Martins ${ }^{2}$ trabalham em seu livro História da Imprensa no Brasil $^{3}$ (2008) os primórdios da imprensa no país. Segundo ela, A imprensa é ao mesmo tempo objeto e sujeito da história brasileira, ou seja, ao mesmo tempo em que ela participa da história ela passa a ser analisada como um objeto. Na visão das historiadoras, a história do Brasil e da imprensa caminham juntas, se auto-explicam, não há como escrever a história da imprensa sem relaciona-la com a trajetória política, econômica e social e cultural do país, pois sempre existe relação entre imprensa e poder, equilíbrio de dependência e critica, de observação e subserviência, busca de liberdade e censura.

Percebe-se que há uma relação com a mudança no processo político social com as transformações da mídia, e que elas influenciaram nessas mudanças no âmbito político e social. Peter Burke $^{4}$ em seu livro Uma História Social da Mídia ${ }^{5}$ (2006) faz esse mesmo balanço da mudança da impressa relacionado com as transformações da sociedade, mudanças essas que tiveram importantes consequências culturais e sociais. Burke discute o desenvolvimento da mídia e seus diferentes gêneros ao longo do tempo e o modo como era feito a transmissão de conhecimento e a difusão das comunicações. Nesse aspecto, ele dialoga com as autoras, embora ambos trabalhem períodos e contextos diferentes no sentido de que as transformações da sociedade geralmente são acompanhadas pelas mudanças da mídia.

As autoras ainda estudam o entrelaçamento entre imprensa e vida política no século $\mathrm{XX}$, foco principal desse projeto. Segundo elas, a passagem da Primeira República, O Movimento de 30 e Estado

\footnotetext{
${ }^{1}$ Possui graduação em História pela Universidade de São Paulo (1981), mestrado em História Social pela Universidade de São Paulo (1989) e doutorado em História Social pela Universidade de São Paulo (1996). Tem experiência na área de História, com ênfase em História do Brasil República, atuando principalmente nos seguintes temas: Historiografia, História Social da Cultura, História da Imprensa, História dos Intelectuais, construção dos discursos em torno da nação e do nacionalismo. Atualmente desenvolve pesquisa sobre a imprensa, entre as décadas finais do XIX e os primeiros decênios da centúria seguinte. (Fonte: Currículo Lattes)

2 Possui graduação em História pela Universidade de São Paulo (1970), mestrado em História Social pela Universidade de São Paulo (1990) e doutorado em História Social pela Universidade de São Paulo (1998). Tem experiência na área de História, com ênfase na História do Brasil atuando nos seguintes temas: História do Brasil Império e República, História de São Paulo, Patrimônio Cultural, História do Café, História da Imprensa, Periodismo e Revistas. (Fonte: Currículo Lattes) 3 MARTINS, Ana Luiza e LUCA, Tania Regina - História da Imprensa no Brasil. São Paulo: Editora Contexto. (2008)

${ }^{4}$ Peter Burke (1937, Stanmore, Inglaterra) foi professor de História das Ideias na School of European Studies, da Universidade de Essex, e deu aulas por dezesseis anos na Universidade de Sussex. Atualmente é professor emérito da Universidade de Cambridge. Especialista em Idade Moderna europeia, enfatiza em suas análises a relevância dos aspectos socioculturais. Foi professor-visitante do Instituto de Estudos Avançados da Universidade de São Paulo (IEA-USP) de setembro de 1994 a setembro de 1995, período em que desenvolveu o projeto de pesquisa "Duas crises de consciência histórica". É autor de mais de trinta livros, muitos deles publicados no Brasil, como O que é história cultural?, A fabricação do rei, Hibridismo cultural e Uma história social do conhecimento. Em parceria com sua mulher, a brasileira Maria Lúcia Garcia Pallares-Burke, escreveu Repensando os trópicos: um retrato intelectual de Gilberto Freyre, obra que se apoia em ampla pesquisa para construir uma narrativa substancial sobre a vida e o trabalho do sociólogo. Seu último livro publicado no Brasil é O historiador como colunista (2009), uma coleção das suas colunas para o jornal Folha de São Paulo.

${ }^{5}$ BURKE, Peter; BRIGGS, Asa. Uma história social da Mídia: De Guttenberg a Internet. 3. ed. Rio de Janeiro: Zahar, 2004-2006.
} 
Novo, o advento do rádio na década de 1920, a inauguração da televisão em 1950 influi no que colocam como veículo impresso ocupando e mantendo seu papel de quarto poder mobilizando decisivamente o destino do país ao mesmo tempo em que Burke trabalha o conceito de imprensa e mercado, uma vez que programas e telenovelas estimulavam e estimulam o telespectador a comprar fazendo com que as notícias sejam vistas como mercadorias.

Burke desenvolveu a interação entre meios de comunicação. Um exemplo desse conceito de interação é o surgimento da imprensa de Gutenberg. Quando apareceu esse novo gênero de comunicação (no caso a impressão gráfica) os outros não sumiram, caso da televisão e do cinema que coexistem, bem como o rádio. Um exemplo citado na obra é Inglaterra do século XVII, onde as canções populares impressas muitas vezes eram usadas como apoio às performances comparando com os karaokês hoje em dia.

$\mathrm{O}$ autor coloca que independente da época, sempre houve troca de informações. Com a revolução dos meios de comunicação, as pessoas conseguiram mais informação e entretenimento. Desde a Idade Média já existia a relação de trocas de informação através da fala, dos gestos e das imagens. Hoje em dia essa relação de trocas se dá pela escrita, pelo rádio, televisão, internet e fotos. Em resumo as mídias oral e impressa coexistiam e interagiam.

\section{RESULTADOS E DISCUSSÃO}

De acordo com Armado Nogueira, diretor da Central Globo de Jornalismo em 1989, Alberico de Souza Cruz e o editor Ronald Carvalho alteraram a edição que tinha sido transmitida no Jornal Hoje. Segundo esses diretores, o presidente da emissora Roberto Marinho e seu filho João Roberto Matinho, pediram para alterar a edição do Jornal Hoje que havia sido manipulado a favor de Lula. Octavio Tostes, editor de texto do Jornal Nacional na época, diz na entrevista que o então editor de política da Rede Globo, Ronald de Carvalho, tinha orientado que era para mostrar os melhores momentos de Collor e os piores momentos de Lula, sendo assim, desequilibrava a edição do Jornal hoje, favorecendo claramente o candidato Fernando Collor de Melo.

Depois dessa reportagem Fernando Collor de Mello teve uma crescente alta nas últimas pesquisas de intenção de voto ficando à frente de Lula a três dias da eleição, tendo em vista que antes do debate os dois candidatos estavam tecnicamente empatados. Posteriormente, Collor foi eleito presidente do Brasil com 53,03\% dos votos contra 46,97 de Lula. Na edição do dia seguinte do Jornal Nacional, a Rede Globo fez uma matéria em que mostrava os melhores momentos do debate, privilegiando o candidato Collor. Seguindo a linha teórica dos autores da Escola de Frankfurt, é possível notar que a matéria do Jornal Nacional, fez uso dessas duas imagens para formar sobre eles a opinião pública, através da edição do debate ao mostrar os melhores momentos. 
TABELA 1

\begin{tabular}{|l|l|l|l|}
\hline \multicolumn{2}{|l|}{ MELHOR DESEMPENHO } & \multicolumn{3}{l|}{ IDEIAS MAIS CLARAS } \\
\hline COLLOR & $44,5 \%$ & COLLOR & $45 \%$ \\
\hline LULA & $32 \%$ & LULA & $34,1 \%$ \\
\hline O MAIS PREPARADO & $48 \%$ & \multicolumn{1}{|l|}{ MELHORES PLANOS } \\
\hline COLLOR & COLLOR & $45,9 \%$ \\
\hline LULA & $30 \%$ & LULA & $33 \%$ \\
\hline
\end{tabular}

Fonte: Instituto Vox Populi

\section{CONCLUSÕES}

A partir da discussão feita nessa pesquisa, é possível desenvolver novos estudos e debater a relação que a mídia tem com a política especialmente no Brasil. Através dos dados coletados e de proposições dos livros que discutem mídia no trabalho não chegamos a uma conclusão definitiva das relações entre mídia e poder mas podemos questiona-la sobre o seu papel na política e de como ela age em favor de seus interesses.

Além de compreender as razões por qual a mídia em geral interfere na sociedade e na política é também importante debater a trajetória da mídia ao longo do tempo relacionando suas mudanças no decorrer da história com as transformações da sociedade. É importante também analisar até que ponto a influência social interfere na mudança e na transformação da mídia ou se a mesma produz efeitos decisivos na sociedade. Ou até mesmo se estão interligadas.

Existem estudos importantes sobre a televisão e os telejornais no Brasil, desenvolvidos de forma específica na área de comunicação social. Cabe destaque para o campo de pesquisa desenvolvido por Adolpho Queiróz a respeito do marketing político e sua influência em eleições.

A presente proposta está em sua abordagem inicial e tem como escopo apresentar suas primeiras reflexões utilizando para tanto o recurso da discussão historiográfica. Uma pesquisa mais profunda será retomada posteriormente dando continuidade às indagações aqui produzidas. 


\section{REFERÊNCIAS}

ARQUIVO VEJA. Coleções, Fernando Collor de Mello. Disponível em < http://origin.veja.abril.com.br/arquivo_veja/fernando-collor-de-mello-confisco-pc-fariasimpeachment-casa-da-dinda.shtml> Acesso em 12 nov. 2017.

BORDENAVE, José E. Diaz. O Que é Comunicação. São Paulo: Brasiliense, 1997.

BOURDIEU. Pierre. Sobre a Televisão. Trad. Maria Lucia Machado. Rio de Janeiro: Jorge Zahar Ed., 1997.

BRIGGS, Asa. BURKE, Peter. Uma História Social da Mídia. De Gutemberg à Internet. Trad. Maria Carmelita Pádua Dias. 2ªed. Rio de Janeiro: Jorge Zahar Editor, 2004.

BURKE, Peter; BRIGGS, Asa. Uma história social da Mídia: De Guttenberg a Internet. 3. ed. Rio de Janeiro: Zahar, 2004.

CARDOSO, Ciro Flamarion. VAINFAS, Ronaldo (orgs). Novos Domínios de História. Rio de Janeiro: Elsevier, 2012.

DA REDAÇÃO. Edição de debate pelo "JN" em 1989 causou polêmica. Disponível em <http://www1.folha.uol.com.br/fsp/brasil/fc3009200622.htm> Acesso em 10 nov. 2017.

DORNELES, Hermy Juliano. A Intervenção da mídia na política - Liberdade de imprensa X democracia.

Disponível em <https://hermy.jusbrasil.com.br/artigos/179006500/a-intervencao-da-midia-napolitica-liberdade-de-imprensa-X-democracia Acesso em 8 nov. 2017.

GUSTAVOCURI. Edição Polêmica do JN - Último debate 89. Disponível em < https://www.youtube.com/watch?v=rJ3rudZ2odA> Acesso em 15 nov. 2017.

LUZEROS. Edição do debate das eleições de 1989 na Globo. Disponível em < https://www.youtube.com/watch?v=YTWVvV8hiYA> Acesso em 15 nov. 2017

MARTINS, Ana Luiza e LUCA, Tania Regina - História da Imprensa no Brasil. São Paulo: Editora Contexto. (2008)

NEVES, Flora. Telejornalismo e Poder nas eleições presidenciais. São Paulo: Editor Summos, 2008

REMOND, René. Por Uma História Política. Trad. Dora Rocha. 2a ed. Rio de Janeiro, FGV, 2003.

SEREZA, Haroldo Ceravolo. Relação com a Globo 'ajudou bastante', lembra Collor; senador diz ter pensado, na véspera, que perderia a eleição. Disponível em <https://noticias.uol.com.br/especiais/eleicoes1989/ultnot/2009/11/15/ult9005u10.jhtm> Acesso em 18 nov. 2017.

SODRÉ, Nelson Werneck. História da Imprensa no Brasil. $4^{\mathrm{a}}$ ed. (atualizada). Rio de Janeiro: Mauad, 1999. 